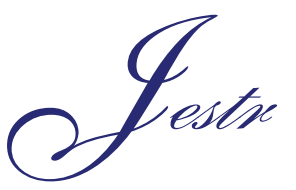

\title{
Decay of Electrical Charges on Polyethylene Terephthalate Surface
}

\author{
L. Herous, M. Remadnia*, M. Kachi and M. Nemamcha \\ Laboratoire de Génie Electrique de Guelma (LGEG). Université de 8 mai 1945, B.P 401 - 24000, Guelma, Algérie.
}

Received 9 January 2009; Revised 21 June 2009; Accepted 5 July 2009

\begin{abstract}
Surface potential decay (SPD) characteristics of a corona charged polyethylene terephtalate (PET) are investigated experimentally. A negative corona discharge produced in a needle - grid - plate electrode system was employed to charge the surface of the film samples (thickness: $0.5 \mathrm{~mm}$; surface: $50 \mathrm{~mm}$ x $50 \mathrm{~mm}$ ). The temperature effect, initial potential and relative humidity are presented. The variation domains for the three factors were respectively: 20 to $60^{\circ} \mathrm{C} ;-1000$ to $-1800 \mathrm{~V} ; 20$ to $80 \%$. All surface potential decay measurements were carried out in a commercial climatic chamber, where relative humidity RH and temperature T were rigorously controlled. The aim of the present work is to demonstrate the effectiveness of the Experimental methodology for evaluating the effects of these factors. This investigation has showed that the surface potential decay is highly conditioned by temperature, relative humidity and charge density initially lay down on the material. Charge injection mechanism in material bulk seems to be the more probable hypothesis to explain charge flow in PET. More over, the experiment results confirm the influence and the role of thermal activation and electrical field on the potential decay.
\end{abstract}

Keywords: Surface Potential Decay, Corona Discharge, PET, Charge Injection, Polarization.

\section{Introduction}

Since several years, synthetic polymers have known a large application in electrical industry due to their excellent electrical, thermal, and mechanical properties. At the same time, solid insulating polymers are used in hostile environments where they may be subjected to water attack, high static non-ionizing radiation and other corrosive materials or reactions. Therefore, the insulation properties are deteriorated and involved a premature ageing of electrical insulation.

Electrostatic charges can play an undesired role in diverse industrial applications, particularly in plastic industry and in highimpedance circuitry. The main fields of industry source of numerous work on surface potential decay are: Electrooptics (photocopies and laser printers) [1-2-3], electrets materials [4-5-6] and electrical industry working on insulating polymer developments for high voltage insulation [7-8-9-10-11].

It is therefore important to have appropriate knowledge on generation and decay of surface charges. The optimization of their performance requires the elucidation of charge transport processes. One of the experimental techniques to investigate the charge carrier transport in solid insulating polymers is the surface potential decay method. Its main interest being to avoid any contact with the surface, provided that charge is deposited by means of a DC corona discharge and that potential is measured by a vibrating reed probe, or by an induction probe. The critical issue concerning potential decay measurements is the interpretation of the curves.
Many experimental works have been carried out with this powerful method [7-12-13-14-15-16]. The great diversity of parameters influencing these mechanisms makes difficult the study and the interpretation of the processes. Several physical processes can be held responsible for the potential decay after corona charge deposit which are: Surface conduction [4-17], polarization phenomena [18], charge injection [19-20], and atmospheric neutralization [21]. One can add also the possible effects of piezoelectric phenomena under the influence of electrostatic pressure at high field.

However, the recent literature on potential decay measurements is dominated by the hypothesis of injection and polarization phenomenon of the charge deposited on the surface. The "Cross-over" of the curves which reported initially by Ieda and co-Workers [7] on polyethylene and has also been observed by other research works [8-25-26] is widely admitted as an experimental evidence of a partial injection into the bulk of the charge deposited on the surface. The amount of charge injected depends on the initial potential value [12-24]. In this work we presented experimental measurements on $0.5 \mathrm{~mm}$ thick PET which we not considered in the past by similar studies. Other results on PET thin film (only samples of $\mu \mathrm{m}$ were studied previously) are also discussed. The obtained results analysis leads to the conclusion that charge injection mechanism can explain the surface potential decay and provides an evidence for the importance of the charging condition.

* E-mail address: remadnia.m@gmail.com

ISSN: 1791-2377 C 2009 Kavala Institute of Technology. All rights reserved. 


\section{Experiment}

\subsection{Samples}

The material used is a polyethylene terephtalate (PET) which belongs to the thermoplastic family. The PET is often used as a dielectric in high performance foil capacitor [25], electric cables and insulation of electric motors coils. The samples used in the experiment are square sheet of $5 \mathrm{~cm}$ side length of $0.5 \mathrm{~mm}$ thickness. One face of the samples was coated by silver paint, to ensure a good contact with the mirror-polished metal plate on which they were laid.

\subsection{Experimental details}

The usual arrangement for studying potential decay using corona charged samples is shown in Figure 1.

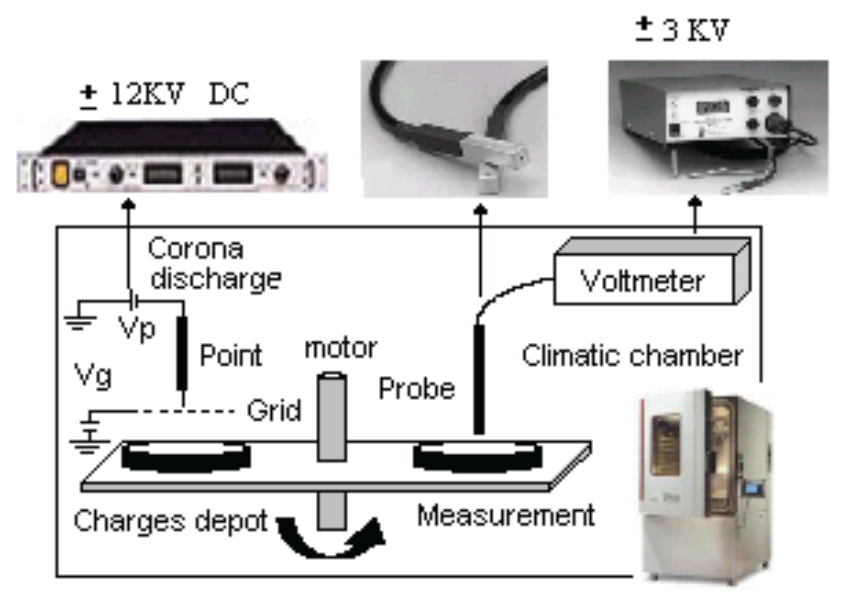

Figure 1. Experimental setup

The samples were charged on their free surface by exposure to a corona discharge generated by a needle electrode situated above the grounded metallic plate and connected to a negative DC high-voltage supply Vp. A grid electrode, connected at a different negative DC potential Vg, was interposed between the needle electrode and the grounded plate. In this way, a reasonably uniform field could be generated in the gap between the grid and the surface of the PET samples.

After charging, the turntable was rotated under a non-contacting probe. The probe is connected to an electrostatic voltmeter (Monroe type), which transmits data to the computer. The surface potential was then measured and continuously recorded. All operations are controlled by a computer.

All the measurements of surface potential decay were carried out in situ, in a commercial climatic chamber, in which humidity and temperature were controlled. The duration of sample exposure to the corona discharge was 1s. Prior to corona exposure, the samples were maintained for one hour in the conditions prescribed for each experiment.

\section{Results and Discussion}

\subsection{Temperature influence}

Figure 2 shows the surface potential decay after negative corona charge deposition for different values of temperature at a fixed relative humidity of $50 \%$. The charge deposit initial potential Vo is of $-1800 \mathrm{~V}$. We noted a fast initial decay at all temperatures and becomes more important with the temperature increases.

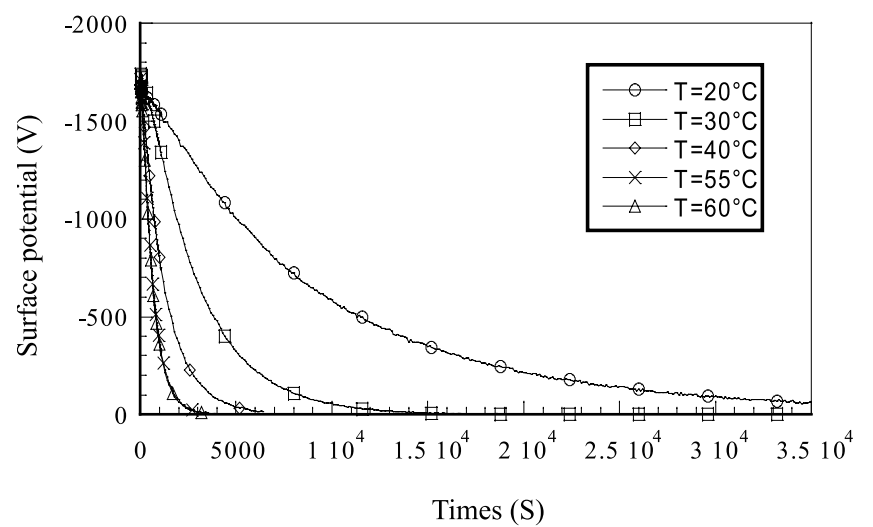

Figure 2. Surface potential decay for different temperature values with $\mathrm{RH}=50 \%$ and $\mathrm{Vo}=-1800 \mathrm{~V}$

We can also notice after some hours, the potential decay become equal to zero. It is very clear that the influence of the temperature play a most important role and acts on the kinetics of the potential decay. Perhaps, this influence is based on a great thermal activation.

\subsection{Initial potential effect Vo}

Figure 3, shows a characteristic family of $\mathrm{V}(\mathrm{t})$ curves after negative corona charging under the same charging condition $\left(\mathrm{T}=55^{\circ} \mathrm{C}\right.$, $\mathrm{RH}=50 \%$ ) but different charging levels.

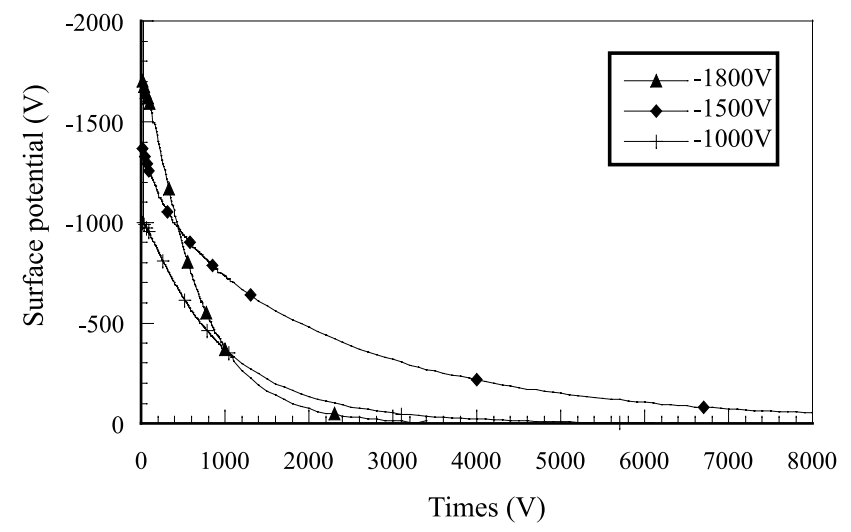

Figure 3. Surface potential decay for various initial potential with $\mathrm{RH}=50 \%$ and $\mathrm{T}^{\circ}=55^{\circ} \mathrm{C}$

The decays are different and there is a marked influence of initial potential. It is noted a fast initial decay and an interesting cross-over phenomenon in which material surface initially charged 
to a high potential show more rapid decay than those charged to a lower potential. It was assumed that the charge deposited on the PET penetrated into the polymer bulk and the charge injection depends on the charging level.

This initial fast decay may be attributed to the partial injection of the deposited charges into the polymer bulk under the electrical field generated by the charges themselves, and this trend was enhanced by raising Vo. Once injected into the bulk, the electrons may be expected to drift towards the back electrode under the influence of this field.

\subsection{Humidity influence}

Figure 4 shows the relative humidity effect on temporal evolution of the potential decay at a fixed temperature of $55^{\circ} \mathrm{C}$. The initial potential for charge deposit is equal to $-1800 \mathrm{~V}$.

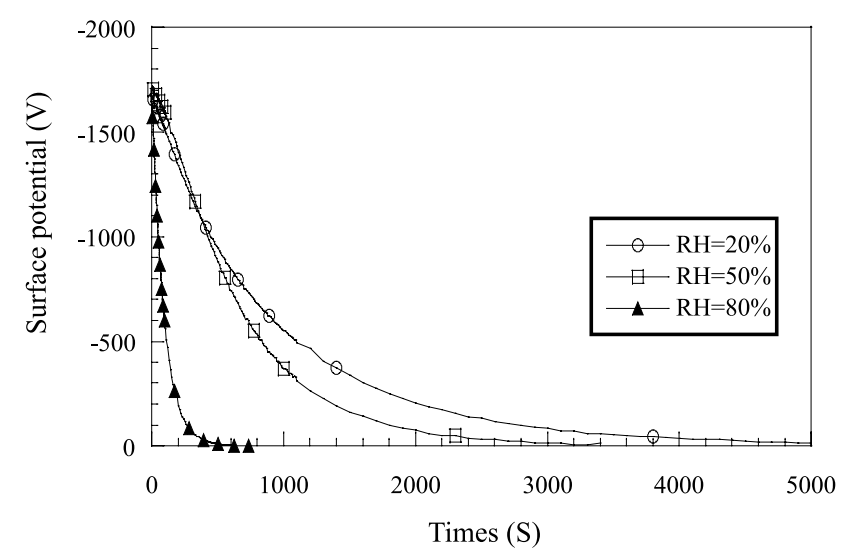

Figure 4. Surface potential decay for different values of Relative humidity with $\mathrm{T}^{\circ}=55^{\circ} \mathrm{C}$ and $\mathrm{Vo}=-1800 \mathrm{~V}$

In most research works carried out on SPD, humidity effect was not taken into consideration and was often neglected $[18,20]$. It is noticed that the humidity acts strongly on the kinetics of the potential decay during all the measurement time. It becomes more important as the humidity increases. It is shown that relative humidity forms an important parameter in the charge flow process of PET surface.

\section{4. $\mathrm{dV} / \mathrm{dt}$ transformation}

Investigating decay characteristics of surface potential of corona charged polymers [20-26-18], it was showed that $\mathrm{dV} / \mathrm{dt}=\mathrm{f}(\mathrm{t})$ presentation in bilogarithmic coordinates is proportional to a current and, is an appropriate mean to explain the most probable mechanism taking place in the charge flow process insulating surface.

To establish the link between potential decay and absorption current which are linked principally to a slow polarization mechanism of material, Molinié [18] has shown in his work on epoxy resin that the material polarization mechanism gives an absorption current according to Curie-von Schweidler law. According to the same author, the potential decay curves are described by the power law $I(t)=A t^{-n}$, which is similar to absorption current.

Therefore, this assumes a polarization phenomenon predominance of surface potential decay in this material.

On the other hand, Von Berlepch [20] and Bigarré [26] have observed in their study on the polyethylene from this representation two straight lines with different slopes.

The authors have explained that this behavior is a representation of charge partial injection mode into the material bulk.

Figure 5 presents a characteristic family of $\log (\mathrm{dV} / \mathrm{dt})$ versus $\log (\mathrm{t})$, curves obtained after negative charging with different initial potential.

These curves shown an intersection of two straight lines, this behavior corresponds to charge injection mechanism explaining the surface potential decay.

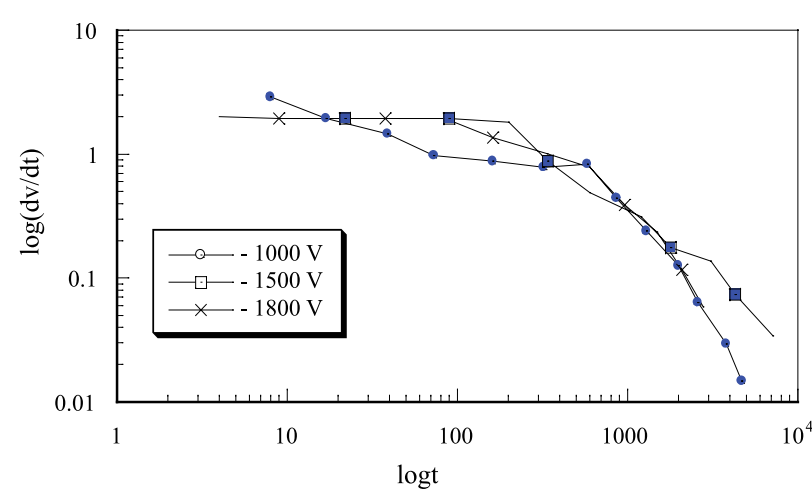

Figure 5. $\log (d V / d t)-v s-\log (t)$ for various initial potential: $\circ=-1000 \mathrm{~V}$, $\square=-1500 \mathrm{~V}, \times=-1800 \mathrm{~V}$

\section{Conclusion}

The present investigation has shown the importance and the role of the temperature and the humidity in charge flow process evolution at PET surface. The initial decay rate increase with increasing temperature and charge moves faster at elevated temperatures. It is assumed, that the physical phenomenon that governs the potential decay is thermally activated. The study has revealed also an interesting cross-over phenomenon. The combination of $\mathrm{dV} /$ dt transformation and taking into account the cross-over phenomenon, charge injection mechanism in material bulk under the electrical field generated by the charge themselves seems to be the probable hypothesis to explain charge flow in PET. Once injected into the polymer bulk, the charges may be expected to drift towards the back electrode under the influence of this field. This study has demonstrated the importance of the experimental methodology for evaluating the effects of the relative humidity and temperature. 


\section{References}

1. I.P. Batra, K.D. Kanazawa, H. Seki, "Discharge characteristics of photoconducting insulators", J. Appl. Phys., Vol. 41, No. 8, pp. 3416-3422, (1970).

2. D.W. Vance, "Surface Charging of Insulators by Ion Irradiation", J. Appl. Phys., Vol. 42, No. 13, pp. 5430-5443, (1971).

3. R.H. Young, "Kinetics of Xerographic Discharge by Surface Charge Injection", J. Appl. Phys., Vol. 72, No. 7, pp. 2993-3004, (1992).

4. G.M. Sessler, C. Alquie, J. Lewiner, "Charge Distribution in Teflon FEP (fluoroethylenepropylene) Negatively Corona-Charged to High Potential", J. Appl. Phys., Vol. 71, No. 5, pp. 2280-2284, (1992).

5. G.M. Sessler, "Charge Storage in Dielectrics", IEEE. Trans. Elec. Insul., Vol. 24, No. 3, pp. 394-402, (1989)

6. R.A. Moreno, B. Gross, "Measurement of potential buildup and decay, surface charge density, and charging currents of corona-charged polymer foil electrets", J. Appl. Phys., Vol. 47, No. 8, pp. 3397-3402, (1976).

7. M. Ieda, G. Sawa, I. Shinohara, "A decay Process of Surface Electric Charges across Polyethylene Film", Japan. J. Appl. Phys., Vol. 6, pp. 793-794, (1967).

8. T. Mizutani, T. Oomura, M. Ieda, "Surface Potential Decay in Polyethylene", Japan. J. Appl. Phys., Vol. 20, pp. 855-859, (1989).

9. R. Coelho, "The electrostatic Characterization of Insulating Materials", J. Electrostatics, Vol. 17, No. 1, pp. 13-27, (1985).

10. H.J. Wintle, "Decay of Static Electrification by Conduction Processes in Polyethylene", J. Appl. Phys., Vol. 41, No. 10, pp. 4004-4007, (1970).

11. P. Llovera, P. Molinié, "Charge injection dynamics on thin films: Limited by surface detrapping or by charge drift mobility? A new contribution using surface potential measurements", $3^{\text {rd }}$ Conf. Société Française d'Electrostatique, Toulouse (2002).

12. H.J. Wintle, "Surface-Charge Decay in Insulators with Nonconstant Mobility and with Deep Trapping", J. Appl. Phys., Vol. 43, No. 7, pp. $2927-$ 2930. (1972).

13. M. Debska, "Surface Potential Decay on Triglycine Sulfate Crystal", J. Electrostatics, Vol. 63, No. 11, pp. 1017-1023, (2005).

14. G. Chen, Z. Xu, L. W. Zhang, "Measurement of the Surface Potential Decay of Corona-Charged Polymer Films Using the Pulsed Electroacoustic Method", J. Measurement Science and Technology, Vol. 18, No. 5, pp. 1453-1458. (2007).
15. P. Molinié, "Charge Injection in Corona-Charged Polymeric Films: Potential Decay and Current Measurements", J. Electrostatics. Vol. 45, No. 4, pp. 265-273. (1999)

16. L. Herous, M. Nemamcha, M. Remadnia, L. Dascalescu, "Factors that influence the surface potential decay on a thin film of polyethylene terephtalate (PET)", J. Electrostatics, Vol. 67, No. 2-3, pp. 198-202, (2009).

17. P. Jestin, R. Coelho, M. Goldman, "Surface Potential Decay on Epoxy Resin", Inst. Phys. Conf. Ser. No 85, Sect. 2, pp.193-196, (1987).

18. P. Molinié, M. Goldman, J. Gattelet, "Surface Potential Decay on Coronacharged Epoxy Samples due to Polarization Processes", J. Phys. D: App. Phys., Vol. 28, No 8, , pp. 1601-1610, (1995).

19. M. Ieda, G. Sawa, U. Schinohara, "Decay of Electric Charges on Polymeric Films", Electric Eng. Japan, Vol. 88, No 6, pp. 67-73, (1968).

20. H.V. Berlepsch, "Interpretation of Surface Potential Kinetics in HDPE by a Trapping Model”, J. Phys. D: Appl. Phys., Vol. 18, No 6, pp. 1155-1170, (1985).

21. R. Coelho, L. Levy, D. Serrail, "On the Natural Decay of Corona Charged Teflon Sheet" IEEE, IAS 84 : 36C, pp. 1033-1037, (1984).

22. E.A. Baum, T.J. Lewis, R. Toomer, "Decay of Electrical Charge on Polyethylene”, J. Phys. D: Appl. Phys., Vol. 10, No 4, pp. 487-497, (1977).

23. S. Salhi, A. Bellal, Z. Ziari, A. Kahlouche, Y. Segui, "Measure and Analysis of Potential Decay in Polypropylene Films After Negative Corona Charge Deposition", J. Electrostatics, Vol. 57, No 2, pp. 169-181, (2003).

24. P. Molinié, "Potential Decay Interpretation on Insulating Films: Necessity of Combining Charge Injection and Slow Volume Polarization Process" Proc. $7^{\text {th }}$ Int. Conf. DMMA, Bath, pp. 50-55, (1996).

25. E. Neagu, P. Pissis, L. Apekis, J.L. Ribelles, "Dielectric Relaxation Spectroscopy of Polyethylene Terephthalate (PET) Films", J. Phys, D: Appl. Phys., Vol. 30, No 11, pp. 1551-1560, (1997).

26. J. Bigarré, P. Hourquebie, L. Doucet, "Nouveau Dispositif de Mesure de Déclin de Potentiel”, $3^{\text {rd }}$ Conf. Societé Française d'Electrostatique, Toulouse (2002). 